\title{
The Effect Progressive Muscle Relaxation and Deepth Breathing on Ansietas Level Caregiver of Paliative Care Patients
}

\author{
Omi Haryati , Nurhalimah Gunawan, Nurdiana Siahaan* \\ Nursing Departement Health Polytechnick Ministery of Health Jakarta III \\ Jln. Arteri JORR Jatiwarna Kec Pndok Melati- Bekasi, Indonesia \\ ${ }^{*}$ Corresponding author's email: dianasuryani [AT] yahoo.com
}

\begin{abstract}
Emotional mental disorders experienced by caregiver due to treating palliative patients which can threaten the integrity of both internal and external self. The study was conducted to determine the effect of progressive relaxation and deep breathing to reduce anxiety in caregiver when treating palliative patients in hospitals. The design of this study is "experimental quasi pre-post test with control group". In the intervention group given progressive relaxation therapy and deep breathing. The number of samples of this study was 40 respondents in each group (intervention and control). The instrument in this study uses the HARS (Hamilton Anxiety Rating Scale). Data analysis includes univariate analysis carried out to describe the characteristics of each variable measured in the study. Bivariate analysis was carried out to identify the effect of progressive relaxation packages on reducing levels of caregiver anxiety in treating palliative patients. Homogeneity of the characteristics of respondents in two groups, that is variables of age, sex, education, occupation, marital status, duration of illness is done by Chi-Square test. From the results of the study there was no decrease in the response of physical anxiety $(p=0.493)$, cognitive $(p=0.223)$, attitude $(p=0.953)$ and psychological $(p=0.933)$ in the intervention group. As well in the control group $(p>0.05)$ except for the attitude element $(p=0.013)$, The results of this study concluded that there was no significant decrease in anxiety response after intervention in deep breath relaxation and progressive muscle relaxation in caregiver who treated palliative patients.
\end{abstract}

Keywords - Caregiver, palliative care, anxiety, progressive relaxation therapy and deepth breathing

\section{INTRODUCTION}

Health is a healthy physical and mental and social condition and not just a condition without illness or weakness. Emotional mental disorders experienced by the caregiver will be result in mental-emotional disorders. Physical disorders experienced by caregiver due to caring for family members with palliative care can threaten internal and external selfintegrity [1]. External threats can be in the form of germs, viruses, environmental pollution both home and hospital environments. inadequate, food intake, clothing or trauma injuries. International threats are the failure of the physiological mechanisms of the body such as impaired heart function, immune system and pain management the threat of physical disruption that occurs in caregiver's life when treating palliative patients can be a stressor that can cause anxiety stress.

Anxiety is a feeling of fear that is unclear and not supported by the situation, Anxiety is a concern that is not clear and spread, related to feelings of uncertainty and helplessness [1]. This emotional state does not have a specific object experienced subjectively and is communicated interpersonally. When someone feeling anxious, the individual feels uncomfortable, afraid, or may have a hunch, it will be calamitous when he does not understand why the emotion that occurs is happening [2]. This shows that anxiety experienced by individuals or families who care for palliative patients is subjective and not the same as each other.

The stress experienced by caregiver due to treating palliative patients is a stressor originating from the environment or a threat of danger in life both real and unreal. The physiological functions that are affected by the effects of stress due to caring for families with palliative diseases will lead to cognitive, emotional, physiological and social changes. The most frequent negative psychological effects are anxiety, depression and helplessness, which are manifested in the form of distress, disability and discomfort. Relaxation therapy is one of individual therapy that can be used to overcome anxiety problems. The progressive relaxation therapy can reduce anxiety levels. This therapy can be used as a single therapy or in combination with other therapies.

Progressive muscle relaxation therapy is a therapy that aims to provide a sensation of tension and relax certain muscles. This therapy is a movement to tighten and relax muscles in a part of the body at a certain time to give a physical relaxation effect. This relaxation procedure can be used independently or as part of a complex procedure. 


\section{METHOD}

The design used in this study was "Pre-post test with a control group" with a package of progressive relaxation therapy interventions in caregiver when treating palliative patients. The population in this study was the caregiver who treated palliative patients at Marzuki Mahdi Hospital in Bogor. Respondents in the intervention group were existing caregiver in the palliative care room and the control group was the caregiver in the hemodialysis room. (explained by respondents whose whom and who is controlled). Inclusion criteria of respondents, the caregiver who care for palliative patients, can read and write willingly to become respondents. When collecting data, researchers get recommendations from the head of the room for the caregiver who keeps the patients who will become the respondents. Based on calculations it is known that the number of samples in this study was 43 respondents in the intervention group and 43 control groups. Six respondents drop out.The sampling technique was carried out by consecutive sampling.

The intervention group received a progressive relaxation therapy package. Each session is held for 45 minutes. For the control group after pre-test, the caregiver was given leaflets and workbooks without intervention. The post-test was carried out after the progressive relaxation package was completed to measure the decrease in caregiver anxiety.

Univariate analysis was carried out to describe the characteristics of each variable measured in the study. Univariate analysis was carried out by calculating the mean, median, standard deviation, $95 \%$ confidence interval, maximum and minimum values. Presentation of the data of each variable in table form and interpreted based on the results obtained.

Bivariate analysis was carried out to identify the effect of progressive relaxation packages on reducing levels of caregiver anxiety in treating palliative patients. Homogeneity of the characteristics of respondents in two groups, namely the variables of age, sex, education, occupation, marital status, duration of illness is done by Chi-Square test. If the pvalue is large from alpha, the intervention group and the control group can be concluded as homogeneous. Explain to see what the pre and post-test used.

\section{RESULTS}

The results of the study of deep breathing and progressive muscle relaxation influence on the reduction of anxiety levels in caregiver in treating palliative patients at Marzuki Mahdi Hospital in Bogor, which was held from July to September 2018. The number of respondents was 80 people (40 control groups and 40 intervention groups ) according to the inclusion criteria. Both groups carried out pre-test and post-test, the results of which were compared. The results of this study consist of three parts which will be described below.

Table .1 Care Giver Response Analysis in Overcoming Anxietas in the Control Group and the Treatment Group

\begin{tabular}{lccccccccc}
\hline Variable & Group & N & Mean & Median & $\begin{array}{c}\text { Min- } \\
\text { Max }\end{array}$ & SD & SE & T & P value \\
\hline Age & 1. Intrevensi & 40 & 46.68 & 47.00 & $19-69$ & 15.26 & 2.41 & 1.89 & 0.117 \\
& 2. Control & 40 & 48.60 & 49.50 & $22-76$ & 11.53 & 1.8 & & \\
\hline
\end{tabular}

The results of the analysis in table 4.2 explained that from 80 caregivers in this study the average age was 47.70 years with the youngest age 19 years and the oldest 76 years. The results of statistical calculations obtained p-value $0.117>$ from $\alpha 0.05$ so it can be concluded that the age in the intervention group and the control group is equivalent. Based on the data above it can be concluded that there was a decrease in the response of physical and psychological and psychological anxiety in the control group respondents. 
Table 2 Care Giver Response Analysis in Overcoming Anxiety in the Control Group before and after the Treatment of Breath and Progressive Muscle Relaxation (n.80)

\begin{tabular}{|c|c|c|c|c|c|c|c|c|}
\hline Variable & Group & $\mathbf{N}$ & Mean & SD & $\mathbf{S E}$ & CI- 95\% & $T$ & P Value \\
\hline \multirow{3}{*}{ Physical } & After & \multirow{3}{*}{40} & 20.05 & 5.742 & 0.908 & & & \\
\hline & Before & & 20.20 & 5.090 & 0.805 & & & \\
\hline & Defference & & 0.150 & 8.580 & 1.357 & $-2.594-2.894$ & 0.111 & 0.913 \\
\hline \multirow[t]{3}{*}{ Cognitive } & After & \multirow{3}{*}{40} & 11.10 & 4.872 & 0.070 & & & \\
\hline & Before & & 11.00 & 3.389 & 0.536 & & & \\
\hline & Defference & & $-0,1$ & 6.316 & 0.999 & $-2.120-1.920$ & $-0,1$ & 0,921 \\
\hline \multirow{3}{*}{ Atitude } & After & \multirow{3}{*}{40} & 9.92 & 2.291 & 0.362 & & & \\
\hline & Before & & 12.18 & 4.494 & 0.711 & & & \\
\hline & Defference & & 2.250 & 5.453 & 0.862 & $0.506-3.994$ & 2.610 & 0.013 \\
\hline \multirow[t]{3}{*}{ Psychology } & After & \multirow{3}{*}{40} & 18.85 & 4.715 & 0.746 & & & \\
\hline & Before & & 20.88 & 6.052 & 0.957 & & & \\
\hline & Defference & & 2.025 & 8.069 & 1.276 & $-0.555-4.605$ & 1.857 & 0.121 \\
\hline
\end{tabular}

Table 3 Care Giver Response Analysis in the Intervention Group in dealing with anxiety before and after giving breath therapy and progressive muscle relaxation (n.80)

\begin{tabular}{|c|c|c|c|c|c|c|c|c|}
\hline Variable & Group & $\mathbf{N}$ & Mean & SD & SE & CI- $95 \%$ & $\mathbf{T}$ & P Value \\
\hline & After & & 21.65 & 4.764 & 0.753 & & & \\
\hline \multirow{2}{*}{ Physical } & Before & 40 & 20.76 & 5.740 & 0.908 & & & \\
\hline & Defference & & -.0 .875 & 7.083 & 1.120 & $-3.140-1.390$ & -0.781 & 0.493 \\
\hline \multirow[t]{3}{*}{ Cognitive } & After & & 11.58 & 2.669 & 0.422 & & & \\
\hline & Before & 40 & 10.82 & 3.194 & 0.505 & & & \\
\hline & Defference & & $-0,750$ & 3.828 & 0.650 & $-1.974-0.474$ & -1.239 & 0,223 \\
\hline \multirow[t]{3}{*}{ Atitude } & After & & 13.10 & 4.919 & 0.778 & & & \\
\hline & Before & 40 & 13.15 & 3.302 & 0.522 & & & \\
\hline & Defference & & 0.50 & 5.325 & 0.842 & $-1.653-1.753$ & 0.059 & 0.953 \\
\hline \multirow[t]{3}{*}{ Psychology } & After & & 21,10 & 5.310 & 0.840 & & & \\
\hline & Before & 40 & 21.20 & 5.548 & 0.877 & & & \\
\hline & Defference & & 0.1 & 7.479 & 1.183 & $-2.292-2.492$ & 0.085 & 0.933 \\
\hline
\end{tabular}

Based on the data above, it can be concluded that there is a decrease in the response of anxiety in the attitude and psychological response of the intervention group after the intervention.

Table 4 Care Giver Ability Analysis in the Control Group in Overcoming Anxiety before and after Giving Therapeutic Breath and Progressive Muscle Relaxation (n.80)

\begin{tabular}{llccccccc}
\hline \multirow{2}{*}{ Variable } & Group & \multirow{2}{*}{ N } & Mean & \multirow{2}{*}{ SD } & SE & CI- 95\% & T & P Value \\
& & & & & & & & \\
\hline \multirow{2}{*}{ Kognitif } & After & \multirow{2}{*}{40} & 18.95 & 1.137 & 0.223 & & & \\
& Before & 18.80 & 1.413 & 0.180 & & & \\
& Defference & & -0.150 & 1.688 & 0.267 & $0.690-0.390$ & 0.562 & 0.577 \\
\hline \multirow{2}{*}{ Psikomotor } & After & \multirow{2}{*}{40} & 31.62 & 8.880 & 1.404 & & & \\
& Before & 33.85 & 10.366 & 1.639 & & & \\
& Defference & & 2.225 & 13.085 & 2.069 & $-1.960-6.410$ & 1.075 & 0,289 \\
\hline
\end{tabular}

Based on the data above it can be concluded that there is an increase in cognitive abilities in the control group with pValue 0.577 . 
Table 5 Care Giver Ability Analysis in the Intervention Group in dealing with anxiety before and after giving breath therapy and progressive muscle relaxation (n.80)

\begin{tabular}{clccccccc}
\hline \multirow{2}{*}{ Variable } & \multicolumn{1}{c}{ Group } & \multirow{2}{*}{ N } & Mean & \multirow{2}{*}{ SD } & SE & CI- 95\% & \multirow{2}{*}{ P Value } \\
& & & & & & & \\
\hline \multirow{2}{*}{ Kognitif } & After & \multirow{2}{*}{40} & 18.92 & 0.997 & 0.158 & & & \\
& Before & & 18.52 & 1.432 & 0.226 & & \\
& Defference & & -0.4 & 1.751 & 0.277 & $0.960-0.160$ & -1.445 & 0.157 \\
\hline \multirow{2}{*}{ Psikomotor } & After & \multirow{2}{*}{40} & 29.76 & 2.669 & 9.499 & & & \\
& Before & 30.48 & 3.194 & 7.278 & & & \\
& Defference & & 0.7 & 12.181 & 1.926 & $-3.196-4.596$ & 0.363 & 0,718 \\
\hline
\end{tabular}

Based on the data above it can be concluded that there was an increase in cognitive abilities in the intervention group after intervention with $\mathrm{p}$ value 0.157

\section{DISCUSSION}

Palliative patients are mostly treated at home, therefore care giver's responsibility is very large and important in providing care to patients. Based on the results of the study it is known that the main caregivers or significant others are life partners (husband or wife), parents, children, and close family who are responsible for caring for and serving patients.

The caregiver age range in this study is quite diverse with lower economic conditions, and the education level is mostly low. [3] found that age, economy, level of education and sex were influential, although they were not a condition for the success of training in progressive muscle relaxation techniques and deep breathing. But it is quite influential when communication between researchers and respondents.

The results of this study conclude that all participants often experience anxiety due to uncertain psychological and physiological conditions, in addition to the lack of information about the management of emergency at home if the patient's condition decreases. Changes in roles in families since caring for palliative patients contribute to the emergence of anxiety. Another factor is the change in the role experienced by caregiver who must play a role in the household both as a mother or head of the household, economic problems where care for sufferers is quite expensive while most participants come from the lower middle class with the livelihoods of workers, only a few who work as civil servants (PNS). Even though they can use government health insurance for poor families or get help from various parties such as family or government agencies, to get medical services takes a long time because of complicated administration and having to queue with other insurance users. In addition, they also face conditions of patients who are unstable, both physical and emotional conditions so they become worried whether what they have done is right or not, until when this condition will end.

Anxiety experienced by caregiver affects the health condition of caregiver. Often caregiver experiences a decrease in physical health which is marked by difficulty falling asleep, the heart easily beats fast when facing the patient's condition, nausea, body feels stiff and stiff, headaches and dizziness, the body feels weak and uninspired. At the young Giver Care, often the anxiety that arises due to concerns about the future of themselves and their families, this seems very young participants like $\mathrm{R}$ who said that they had dropped out of school and worked odd jobs as parking attendants due to lack of fees and also burdened by having to take care and care for his sick mother.

Physical symptoms experienced by caregiver in treating palliative patients are consistent with the results of this study where caregiver experiences physiological responses due to anxiety as follows: irregular heartbeat, chest pain, shortness of breath or shortness of breath, sweating, muscle spasms, dry mouth, dizziness, headaches, and indigestion, anxiety, nervousness, fainting, feeling weak or numb, insomnia, tightness of the esophagus or a choking sensation, stiff neck or back, cold, nausea or vomiting, abdominal pain, often urinate, and also diarrhea.

While the cognitive symptoms experienced include, assuming he is unable to overcome threats, assuming that no one can help himself and think something bad will happen, worry about something, fear of inability to face problems, difficult concentration, impulsivity. While the psychological symptoms include panic, being impatient, the appearance of opposing feelings at the same time, sensitive, nervous, irritable, agitated and panic, Worried about losing the person being treated, worried about not giving good care, worried about the future of the person being treated and his family [4] $[5]$. 
This study concludes that with relaxation exercises: deep breathing and physiologically stressful relaxation provide a relaxed response, which can be identified by decreased blood pressure, heart rate and increased skin resistance . This breathing relaxation has a function to relax the body by regulating breathing regularly, slowly and deeply, because when our condition feels stressed or anxious, the body will become tense and shortened breathing[6] .

The results of this study are in accordance with the opinions [7] that the anxiety experienced by the caregiver will result in physiological changes due to decreased body immune and damage to the bioplasmatic body which results in weak body and various physical complaints arise. Therefore, the provision of psychological help needs to be given to the caregiver to reduce anxiety and increase body immunity [8]. But after being given a deep breathing intervention and progressive muscle relaxation the care giver's physiological response to the anxiety experienced decreased.

The level of anxiety experienced by the caregiver when it comes to treating palliative patients is very diverse. Mild anxiety experienced by the caregiver when treating palliative patients is a healthy and adaptive response. Because mild anxiety is useful to encourage individuals to use adaptive coping, anxiety can be abnormal if the caregiver has reached the stage of moderate or severe anxiety and even panic because it will lead to threats and disruption in the quality of life [5].

The success of this study was also influenced because the training was given in groups.[9]. revealed that group learning will create interaction between members, the support of giving confidence among group members. So as to allow each group member to learn from different experiences to be a strong and empowering person.

In addition, group learning will have a positive impact where each participant can share stories and experiences. [ 7 ] ] stated that the training that was given in groups had a positive effect, namely when someone was in a group situation with the same characteristics or problems that enabled support for each other to share experiences and exchange information and a feeling of togetherness for caregiver. Interventions carried out in groups will have a positive effect, because respondents are in a group situation that has the same characteristics or problems that allow group members to support one another, sharing experiences between group members and the occurrence of information exchange and the feeling of togetherness among group members and providing support for caregiver. [7]

The results of the implementation of this study also concluded that the implementation time for two weeks was only able to reduce most of the anxiety symptoms experienced by the caregiver. But with the provision of material that is simple and applicable, the caregiver can do the exercises independently without always being guided continuously. Care Giver said that the training that has been taught has given a change in their outlook on life. They become more optimistic and passionate about living, able to develop self-control techniques, and able to regulate the emotions and physical of individuals from anxiety, tension, stress and others [10 ].

Every caregiver looks very excited and motivated when attending training on anxiety, deep breathing techniques and progressive muscle relaxation. This is marked by all caregiver always present on time. The caregiver also said that he was happy with the training given because he added knowledge and skills in how to overcome anxiety and disturbances arising from anxiety experienced. At the first meeting, some caregiver already knew how to deal with anxiety with deep breathing and muscle relaxation, but the actions carried out were not structured and irregular so that the resulting effects were less optimal. After being given caregiver training, they say they will do it regularly because the perceived effects are very helpful for the caregiver to reduce anxiety levels. The follow-up that the researcher did so that the ability that had been given to be entrenched was to give workbooks and daily activity notes so that the caregiver did the exercises according to a mutually agreed schedule.

At the second meeting, researchers conducted an evaluation of the caregiver condition and the level of anxiety experienced after the intervention obtained during the training. The evaluation was carried out qualitatively the result was that most caregivers said that deep breathing and progressive muscle relaxation exercises were able to reduce anxiety levels and improve relaxation in caregiver. Care Giver said that the body had started to feel good and no more aches. At the third meeting, researchers conducted a quantitative evaluation of the level of anxiety, cognitive abilities and psychomotor abilities in dealing with anxiety.

Training in progressive muscle relaxation techniques and breathing in giver care that treats palliative patients has been shown to reduce anxiety. Before the intervention, the average anxiety response experienced by caregiver included cognitive, psychological, attitudinal and physiological behaviours after the intervention occurred, decreased anxiety response, namely cognitive giver's cognitive abilities increased and psychological response decreased because caregiver was able to manage anxiety so caregiver became more relaxed. This proves that the process of continuous training and repetition in relaxation is a learning process so that it can improve skills in relaxation and reduce anxiety levels. Repetitive and routine training by care giver at home helps reduce anxiety levels and improves relaxation 


\section{CONCLUTION}

From the results of the study there was a decrease in the level of anxiety in the con trol group before and after deep breath therapy and muscle relaxation, namely physical response with P-Value 0.913 , Cognitive with $\mathrm{P}$ Value 0.921, attitude 0,013 and psychological with P Value 0.121.

There was a decrease in the level of anxiety in the intervention group before and after deep breathing therapy and muscle relaxation physical response with P-Value 0.493 , cognitive $0.223,0.953$ and psychological attitudes with P Value 0.93

In this study there was an increase in the ability of the control group for cognitive respondents with a $\mathrm{P}$ Value of 0.577 while the Psychomotor ability was P Value 0.289

In the intervention group there was an increase in cognitive abilities with $\mathrm{P}$ value 0.157 while psychomotor improvement $\mathrm{p}$ value 0.718 .

There was a better increase in the intervention group than the control group

In this study there was a decrease in the level of anxiety in care giver palliative patients after giving progressive muscle relaxation therapy and deep breathing, but all the results were not meaningf ul.

\section{REFERENCES}

[1]. Stuart, Gail and Laraia, Pocket book of mental health nursing $3^{\text {th }}$ edition, EGC Jakarta , 2005

[2]. Videbeck, S.L.. Psychiatric Mental Health Nursing. ( $3^{\text {rd }}$ edition). Philadhelpia: Lippincott Williams \& Wilkins, (2006)

[3]. Manzoni, G.M., Pagini, F., Castelnuovo, G., \& Molinary,E (2008) Relaxation Training for anxiety: a ten year systematic review with mata-analysis. Bio Medical Central Psychiatry, 2017

[4]. Greenberg, D.,\& Padesky, C.A. Comprehensive Stress Management, $8^{\text {th }}$ edition McGraw-Hill New York, 2002

[5]. Nevid,J.S., Rathus, S.A., \& Greene, B. Abnormal Psychologi $1^{\text {th }}$ edition Jakarta: Erlangga Publishers, 2005

[6] Davis, M., Eshelman,E.R., \& Mc Kay,M.. The Relaxation\& Stress Reduction Workbook. Interpreted 1995. Jakarta: EGC Medical Book Publishers.

[7]. Nijboer, C., Tempelaar, R., Sanderman, R., Triemstra, M., Spruijt, R. J., \& Van Den Bos, G. A. M. Cancer and caregireing: the impac on the caregiver's health. Journal Psycho- Oncology 1998

[8] Deviana, YTogetherness As Psychosocial Therapy For Cancer Patients. . 2007

[9]. Yalom, I. D. The Theory and Practice of Group Psycotherapi. USA: Basic Books. 1985

[10]. Kazdin Behavior Modification in Applied Setting. $6^{\text {th }}$ edition. Wadworth/Thompson Learning. USA 2001. 